\title{
Optic disc duplication or coloboma?
}

\section{N Islam, J Best, J S Mehta, S Sivakumar, G T Plant, W F Hoyt}

Aim: To describe lesions resembling optic disc duplication and highlight their unusual visual fields. The authors also report the first case of pseudo-duplication of the optic disc with overlying retinal nerve fibre layer.

Methods: Retrospective, non-comparative review of case notes. Humphrey visual fields and OCT-3 imaging were performed.

Results: All 11 cases represented peripapillary chorioretinal coloboma, some of which lie superior to the optic disc. A double blind spot or superior hemifield defects can be demonstrated by automated visual field testing.

Conclusion: Clinical examination and identification of bridging retinal vessels from the true optic disc to the second pseudo disc can usually avoid unnecessary invasive and noninvasive investigations.

O tometrists or primary care physicians may detect unexpected field defects or presume disc cupping on routine funduscopy. Eleven lesions simulating duplication of the optic disc are depicted; we highlight some of their apparently unreported field and disc appearances.

True doubling of the optic disc, with a dual system of retinal blood vessels, is rare. In the literature, most cases appear unilaterally and are associated with decreased acuity in the affected eye. ${ }^{1}$ Duplication or separation of the optic nerve into two fasiculi is rare in humans, but common in some lower vertebrates. ${ }^{1}$

\section{METHODS}

This was a non-comparative, retrospective case series. Disc photographs and Humphrey visual fields were obtained from five ophthalmic departments.

\section{RESULTS}

Seven left (fig 1A-D, K-M) and four right (fig 1E-G and J) eyes were affected. At presentation, eight male and three female patients ranged from age 11 to 72 years with a mean age of 36 years. Patient demographics and retinal features are summarised in table 1 .

\section{DISCUSSION}

Typical colobomas are located inferiorly and slightly nasally, resulting from failure of closure of the fetal fissure. The fetal fissure closes first in the region of the equator, with progressive closure anteriorly and posteriorly from that point. Failure of the fetal fissure to close posteriorly results in absence of choroid, pigment epithelium, and retina in that area. ${ }^{2}$ The choroidal net seems to develop wherever mesoderm is in contact with pigmented epithelium. The choroid appears pari passu with the retinal pigment, and closure of the fetal fissure is not always constant. ${ }^{3}$ Case 3 demonstrates a chorioretinal coloboma positioned superior to the optic disc (fig lC). Donoso et $\mathrm{al}^{1}$ have demonstrated such a lesion linked to the true optic disc with retinal vessels. An alternative more plausible hypothesis is that an inflammatory focus caused such a peripapillary chorioretinal coloboma.

We demonstrate a double blind spot by Humphrey automated visual field testing (fig 2A). Two distinct blind spots, revealed only by campimetry, have been mentioned previously only by Collier. ${ }^{4}$ Two patients (cases 4 and 7 ) revealed superior hemifield visual field defects (figs $2 \mathrm{~B}$ and D) on Humphrey automated perimetry. Such typical nerve fibre defects, on Goldmann perimetry, have been previously reported..$^{5}$ Fluorescent fundus angiography (FFA) has been used to differentiate between true doubling and pseudodoubling of the optic disc (case 11), by the absence of a dual

Abbreviations: FFA, fluorescent fundus angiography; OCT, optical coherence tomography

Table 1 Characteristics of 11 patients with peripapillary colobomatous pseudo-duplication of the optic disc

\begin{tabular}{|c|c|c|c|c|c|c|c|c|}
\hline No & Side & $\begin{array}{l}\text { Age (years) } \\
\text { at referral }\end{array}$ & Sex & $\begin{array}{l}\text { Visual } \\
\text { acuity }\end{array}$ & $\begin{array}{l}\text { Location of } \\
\text { "second optic disc" }\end{array}$ & $\begin{array}{l}\text { Coloboma } \\
\text { pigmentation }\end{array}$ & Other features & Unusual visual field \\
\hline 1 & Left & 72 & $M$ & $6 / 6$ & $2 \mathrm{DD}$ inferior & Absent & - & - \\
\hline 2 & Left & 35 & $M$ & $6 / 6$ & $0.5 \mathrm{DD}$ inferior & Present & $\begin{array}{l}\text { Nerve fibre layer over } \\
\text { coloboma on OCT }\end{array}$ & - \\
\hline 3 & Left & 70 & M & $6 / 9$ & $2 \mathrm{DD}$ superior & Present & $\begin{array}{l}\text { Macular congenital } \\
\text { hypertrophy of retinal } \\
\text { pigment epithelium }\end{array}$ & Double blind spot \\
\hline 4 & Left & 20 & $M$ & $6 / 6$ & 1.5 DD inferior & Present & - & Superior hemifield defect \\
\hline 5 & Right & 35 & $\mathrm{~F}$ & $6 / 9$ & 1 DD inferior & Absent & - & - \\
\hline 6 & Right & 22 & $\mathrm{~F}$ & $6 / 6$ & 2 DD inferior & Absent & - & - \\
\hline 7 & Right & 11 & $M$ & $6 / 5$ & 1.5 DD inferior & Present & $\begin{array}{l}\text { Bilateral disc coloboma } \\
\text { Tortuous right inferonasal } \\
\text { branch refinal vein }\end{array}$ & $\begin{array}{l}\text { Bilateral superior hemifield } \\
\text { defect }\end{array}$ \\
\hline 8 & Right & 50 & M & $6 / 6$ & 1.5 DD inferior & Present & - & - \\
\hline 9 & Left & 15 & $\mathrm{~F}$ & $6 / 6$ & 1 DD superior & Absent & - & - \\
\hline 10 & Left & 30 & M & $6 / 5$ & 1.5 DD inferior & Present & - & - \\
\hline 11 & Left & 40 & M & $6 / 6$ & $3 \mathrm{DD}$ inferior & Absent & - & - \\
\hline
\end{tabular}

DD, disc diameter; OCT, optical coherence tomography. 


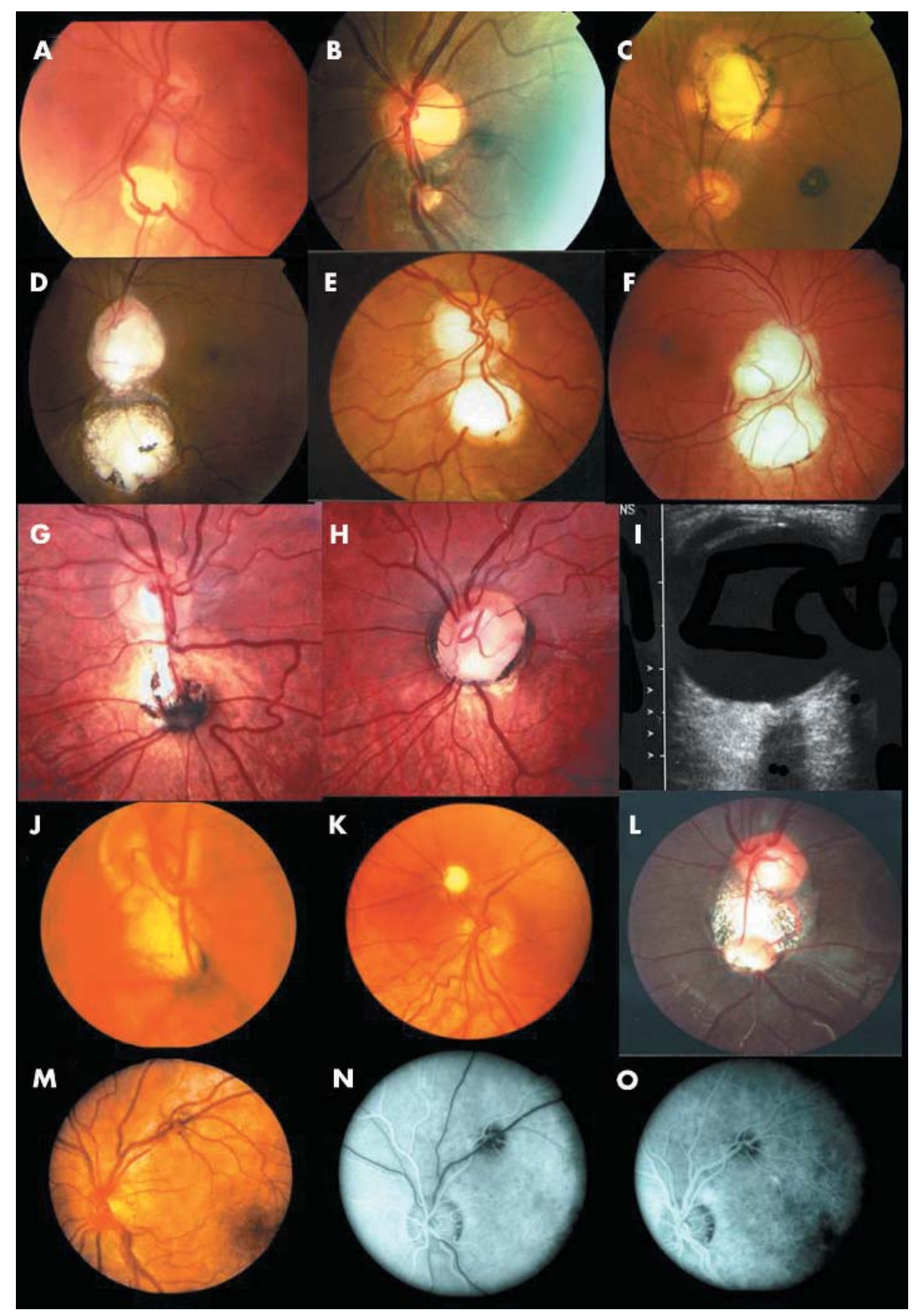

Figure $1 \quad(A-G)$ Disc photographs of cases 1-7 respectively. (H) (case 7) Left inferior disc coloboma. (I) (case 4) Bscan ultrasound showing peripapillary optic disc coloboma and only one optic nerve. (J-M) Disc photographs of cases 8-11 respectively. (N) (case 11) Arteriovenous phase, and (O) late venous phase fundus fluorescein angiography showing absence of dual retinal blood vessels.

system of retinal blood vessels. ${ }^{56}$ Pseudo-doubling has been previously differentiated from true optic nerve duplication by the imaging techniques of ultrasonography, ${ }^{1}$ computed tomography (CT), ${ }^{1}$ and magnetic resonance imaging (MRI). True duplication of the optic disc, in vivo, has yet to be documented by MRI or CT neuroimaging.

The unexpected OCT images (fig 3) can be explained embryologically; the intercalary membrane over the coloboma is derived from what would have become neurosensory retina, and acts as a scaffold for the nerve fibre layer to pass over the colobomatous defect relatively undisturbed. Nevertheless, case 7 demonstrates the inferonasal branch retinal vein undergoing a very tortuous path around the defect (fig lG). Rare cases of true duplication of optic discs with separation of optic nerve into two or more strands have been reported, ${ }^{7}$ based either on incidental necropsy findings, demonstration of two optic foramina in the same orbit on $\mathrm{x}$ ray $^{8}$ or angioscotomas ${ }^{4}$ as indirect evidence of the existence of double optic nerves. Pseudo doubling of the optic discs caused by lesions such as optic disc coloboma, peripapillary chorioretinal coloboma (bilateral ${ }^{6}{ }^{9}$ ), or inflammatory foci are much more common. ${ }^{5}{ }^{10}$

\section{CONCLUSION}

Optometrists and primary care physicians should be aware that all 11 cases of optic nerve head pseudo-duplication represent peripapillary chorioretinal coloboma. These anomalies are asymptomatic and require no treatment. Their position can be superior to the optic disc, and may cause a double blind spot or superior hemifield defects. Identification of bridging retinal vessels from the true optic disc to the second pseudo disc can usually avoid unnecessary invasive and non-invasive investigations. 


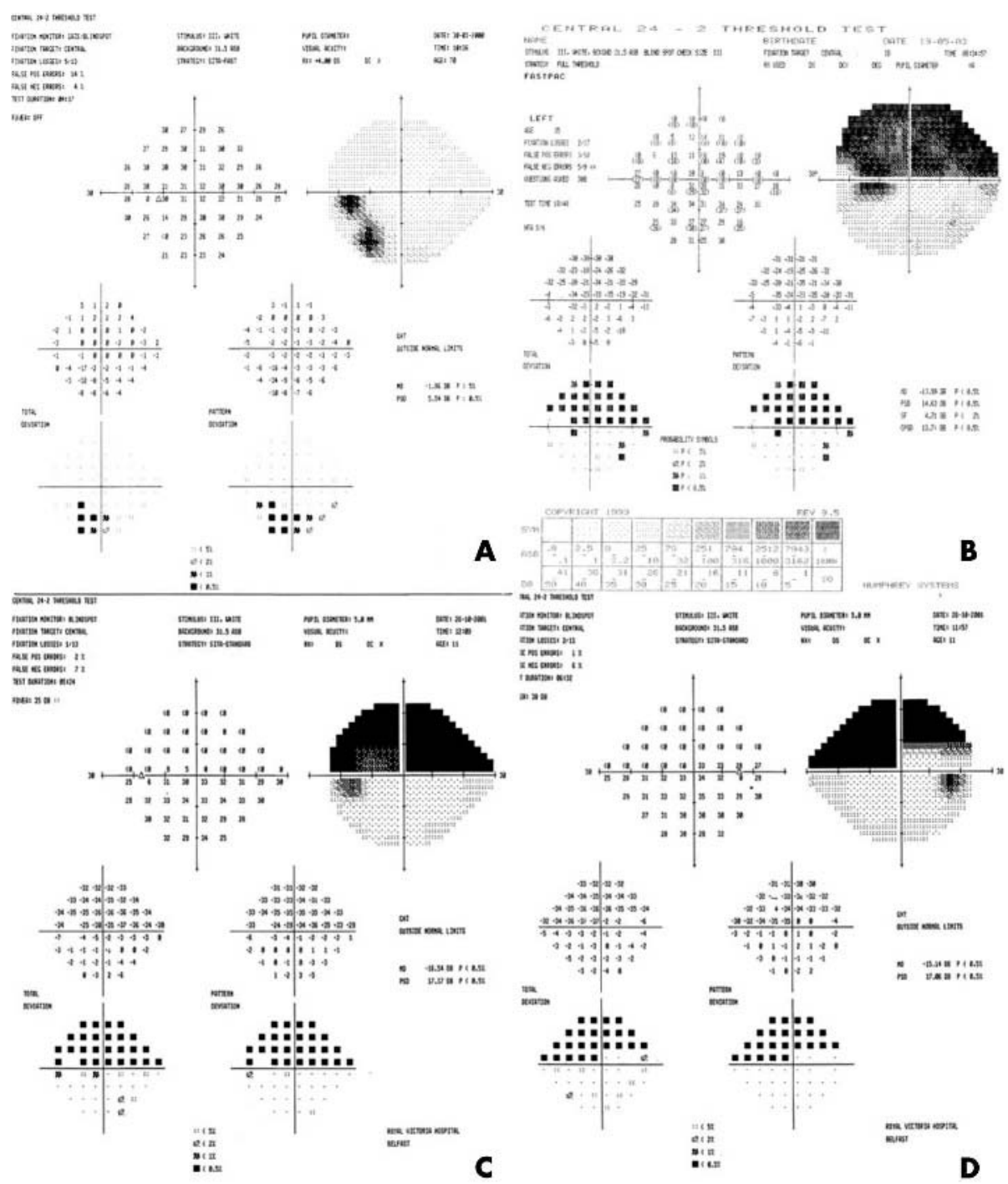

Figure 2 Humphrey visual fields

showing: (A) (case 3) double blind spot,

(B) (case 4) left, (C) (case 7) left, and (D) (case 7) right superior hemifield defects.

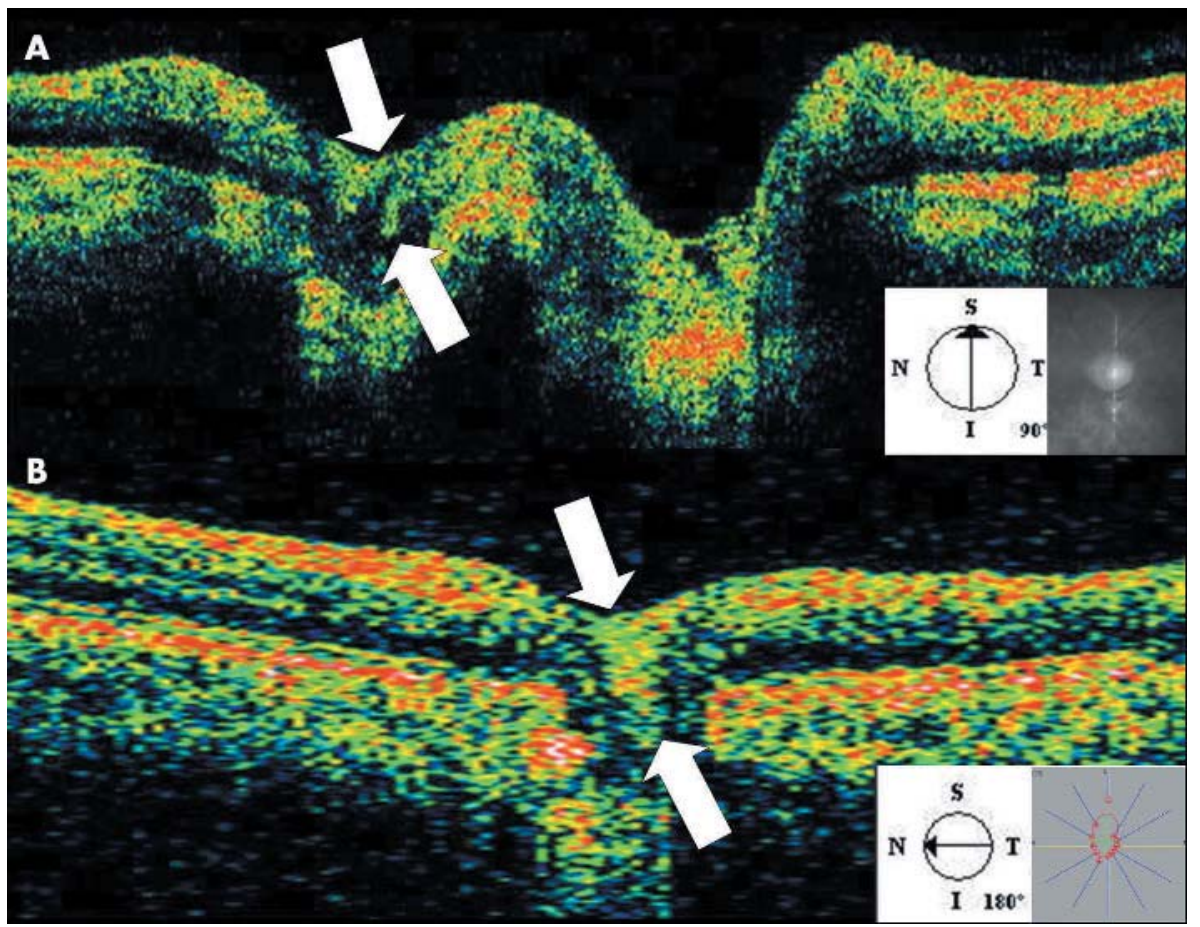

Figure 3 OCT imaging showing $(A)$ relatively undisturbed retinal nerve fibre layer (between two white arrows) passing over colobomatous defect and (B) inferior position of coloboma to true optic disc. 


\section{Authors' affiliations}

N Islam, J S Mehta, G T Plant, Moorfields Eye Hospital, London, UK N Islam, J Best, G T Plant, National Hospital for Neurology and Neurosurgery, London, UK

N Islam, S Sivakumar, Whipps Cross University Hospital Trust, London, UK

J Best, Royal Victoria Hospital, Belfast, Ireland

W F Hoyt, University College of San Francisco, CA, USA

Financial support: None.

Proprietary support: None.

Presentation: Poster and Rapid Fire oral, European Association for Vision and Eye Research (EVER), Alicante, Spain Oct 2003.

Correspondence to: Mr Niaz Islam, Medical Retina, Moorfields Eye Hospital, City Road, London ECIV 2PD, UK; isniaz@yahoo.com

Accepted for publication 24 June 2004

\section{REFERENCES}

1 Donoso LA, Magargal LE, Eiferman RA, et al. Ocular anomalies simulating double optic discs. Can J Ophthalmol 1981;16:85-7.

2 American Academy of Ophthalmology. Ophthalmic pathology and intraocular tumours. Basic clinical and science course. Section IV-3. San Francisco: American Academy of Ophthalmology, 1994:68.

3 Mann I. The development of the human eye, 3rd ed. London: British Medical Association, 1964:38.

4 Collier M. Les doubles papilles optiques. Bull Soc Ophtalmol Fr 1958:71:328-52.

5 Brink JK, Larsen FE. Pseudodoubling of the optic disc. A fluorescein angiographic study of a case with coloboma. Acta Ophthalmol (Copenh) 1977;55:862-70.

6 Hayreh SS, Cullen JF. Atypical minimal peripapillary choroidal colobomata. Br J Ophthalmol 1972;56:86-96.

7 Duke-Elder SS, ed. Congenital deformities. System of ophthalmology, Vol III-2. St Louis: Mosby, 1964:671-2.

8 Lamba PA. Doubling of the papilla. Acta Ophthalmol (Copenh) 1969:47:4-9.

9 Kamath GG, Prasad S, Patwala Y, et al. Peripapillary coloboma simulating double optic disc. Arch Neurol 1980;37:210-13.

10 Barboni P, Deluigi M, De Bonis C, et al. Pseudodoubling of the optic disc. Arch Ophthalmol 1998;116:1400-1.

\section{$\mathrm{ECHO}$}

\section{CYBIPI mutations are a risk for POAG}

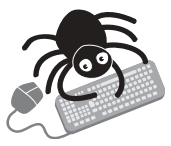

Please visit the British Journal of

Ophthalmology website [www. bjophthalmol. com] for a link to the full text of this article.
- arly treatment to preserve sight should now be possible for some patients at risk of

- visual impairment, thanks to a study showing that CYPIBl mutations in French

Caucasians predispose to primary open-angle glaucoma (POAG). This will be important to relatives potentially at risk in families with the disease. The mutations significantly raise the risk of early onset POAG, though the findings need to be replicated in other ethnic populations.

Eight mutations in the CYP1Bl gene were found among 11 patients (4.6\%) out of 236 unrelated patients with POAG screened for mutations by denaturing high performance liquid chromatography and DNA sequencing, in contrast to just one subject among 197 controls. All of the mutations except one-Y81N, a new mutation found in two of the patients-were known mutations already found in patients with primary congenital glaucoma (PCG). Those patients with the mutations had earlier clinical signs of POAG, with juvenile or middle age onset, than patients without. Seventeen of the patients had MYOC mutation, but none of these had a CYPIBl mutation.

POAG is a widespread cause of blindness with a complex genetic base. Less than $5 \%$ of cases show mendelian inheritance, even though the disease often shows familial clustering, and MYOC mutations account for a mere $2-4 \%$ of cases. In some families POAG segregates with PCG, which is associated with mutations in CYPIBl in many different ethnic groups. These observations suggested that mutations in this gene might also be connected with POAG.

A Melki R, et al. Journal of Medical Genetics 2004;41:647-651. 